\title{
Impact of the Content Variation of the Different Recycled Wastes to the Properties of Concrete Paving Block
}

\author{
X Wang ${ }^{1}$, C S Chin ${ }^{1,2}$ and J Xia ${ }^{1}$ \\ ${ }^{1}$ Civil engineering department, Xi'an Jiaotong-Liverpool University, Suzhou, Jiangsu, 215000, China \\ ${ }^{2}$ Dean of Learning and Teaching \& Former Head of Department, Xi'an Jiaotong-Liverpool University, Suzhou, Jiangsu, 215000, China
}

\begin{abstract}
Recycled concrete aggregates have been widely studied and used in concrete products nowadays. However, other recycled wastes, such as glass, have not been involved too much in recycled aggregate concrete studies. This paper aims to study the impact of the content variation of the different recycled wastes to the properties of the concrete paving block. In this paper, not only recycled coarse concrete aggregates, crushed glass are also used as the recycled aggregate in the concrete paving block in different replacement levels. According to test the properties of blocks mixed with different recycled wastes, the experimental results indicate that: (1) adding recycled concrete coarse aggregate (RCCA) in the blocks can decrease the blocks' strength, and increase the water absorption. The suggested replacement levels for RCCA is $60 \%$; (2) mixing crushed glass (CG) in the concrete paving blocks as a type of coarse aggregates can obviously improve the blocks' strength and decrease the blocks' water absorption.
\end{abstract}

\section{Introduction}

In China, the construction industry has developed rapidly since the late of the 1990s [1]. High-rise buildings are established, and the old buildings and constructions are demolished at the same time. Due to the irreplaceability of concrete in the construction industry, large quantities of concrete needs to be widely used in engineering, and this situation leads to the generation of large volumes of construction waste. Thus, using recycled demolished concrete as the aggregate in the new construction products could reduce the utilization of the limit-resource in nature and reduce the environmental burden at the same time.

However, construction wastes do not only represent recycled concrete aggregates which contain crushed concrete, crushed bricks, and granites. Glass, woods, plastic, rubbers and so on are also counted as construction wastes [2]. Nowadays, concrete paving blocks cast with recycled aggregates have been studies and manufactured in many countries [3-6]. Thus, the concrete paving block is selected as the type of concrete product to be manufactured and investigate in this paper.

In this paper, not only recycled coarse concrete aggregates, the crushed glass are also used to investigate the impact of the content variation of the different recycled wastes to the properties of concrete paving blocks. Plus, for all the experiments in this paper, all the parameters of the production machines, as well as the mode of production, are in accordance with the actual industrial production standards of the company named
Suzhou Construction Material Recycling Application Co., Ltd.

\section{Experimental program}

\subsection{Materials}

The entire materials used in this series of experiments are listed as follow:

- Natural coarse aggregate;

- Natural fine aggregate;

- Ordinary Portland cement compressive strength at 28 days);

$(42.5 \mathrm{MPa}$

- Recycled concrete coarse aggregate (contain crushed concrete, crushed stone, and crushed bricks);

- Crushed glass.

In this experiment, there are two types of construction wastes are used: recycled concrete coarse aggregate (RCCA) and crushed glass (CG). RCCA was collected from a local recycled aggregate manufacture factory. Crushed glass was sourced from a local glass recovery plant and crushed into $5 \mathrm{~mm} \sim 2.5 \mathrm{~mm}$ in the laboratory. Figure 1 shows the graphics of recycled wastes used in this experiment. 


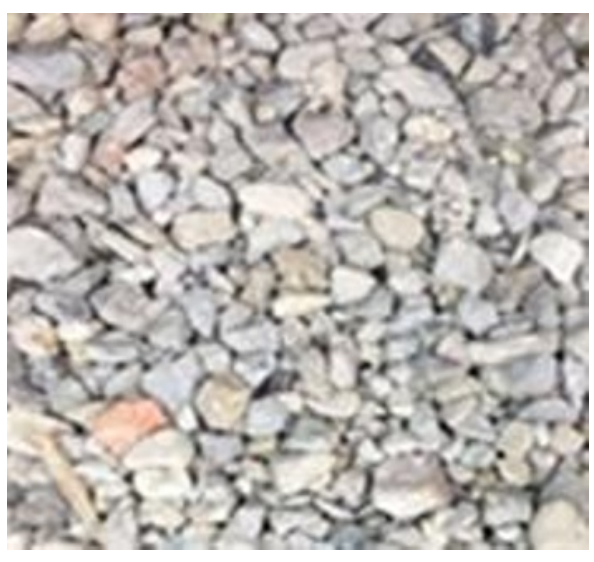

(a) RCCA

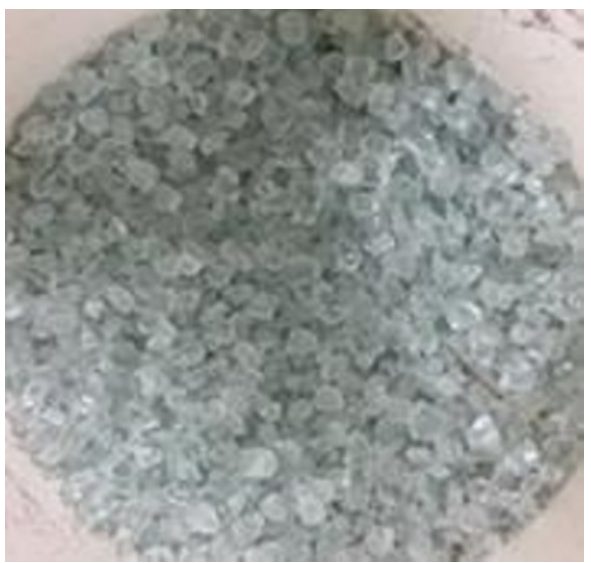

(b) Crushed glass

Figure 1. Characteristics of recycled wastes.

\subsection{Mix proportion and replacement levels}

In order to investigate the impact of the content variation of the different recycled wastes to the properties of concrete paving blocks, two different types of waste materials were used to replace the coarse aggregates in the concrete mixture with 28-days target strength of $30 \mathrm{MPa}$. The original mix proportion was designed according to the "mass method" in Chinese standard JGJ55-2011 [7]. The concrete paving blocks which were cast by replacing the natural coarse aggregate by weight with different replacement levels of recycled materials.

According to the previous articles and experiments results, the replacement levels of RCCA in the experiment were determined as $20 \%, 40 \%, 60 \% 80 \%$ and $100 \%$. As the same as RCCA, crushed glass was also used to replace the coarse aggregates in the blocks. According to the previous articles and trial test results [8], the final replacement levels of crushed glass were decided as $10 \%, 20 \%, 30 \%$ and $40 \%$,

\subsection{Specimens preparation}

The specimens are designed as typical concrete paving blocks. The whole procedures, including preparing the concrete mixture, casting concrete paving blocks and curing, were in accordance with the actual industrial production standards of the company in Suzhou. Plus, the parameters of the production machines (a small hydraulic brick making machine) were set as same as the company's requirements. Figure 2 shows the image of the brick making machine. All the concrete mixtures were sent into the small hydraulic brick making machine to be compacted under $80 \mathrm{kN}$ force to be cast into $200 \mathrm{~mm} * 100 \mathrm{~mm} * 60 \mathrm{~mm}$ concrete paving blocks [9].

\subsection{Test and requirements}

Both British standard BS EN -1338: 2003 [10] and Chinese standard GB 28635-2012 [11] stipulate the requirements for concrete paving blocks. In this series of experiments, four properties of the concrete paving block were tested: Dimensions, compressive strength, tensile splitting strength, and water absorption.

Figure 3 shows the universal test machine (UTM) for testing block's strength

\section{Test results}

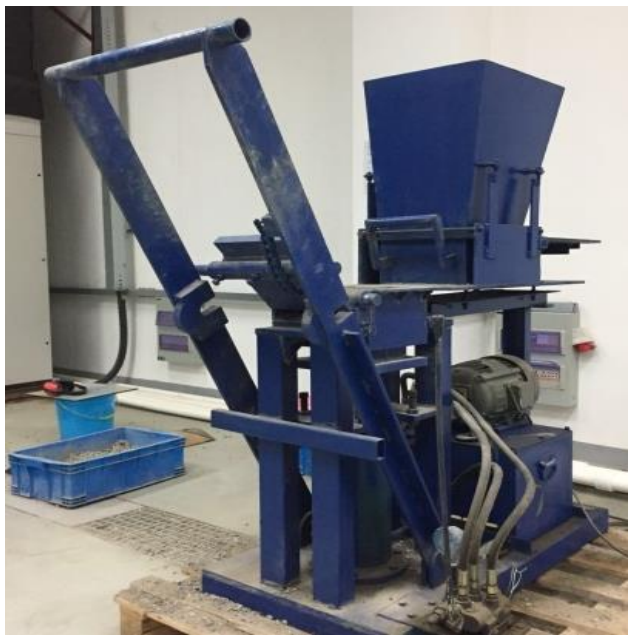

Figure 2. Hydraulic brick making machine.

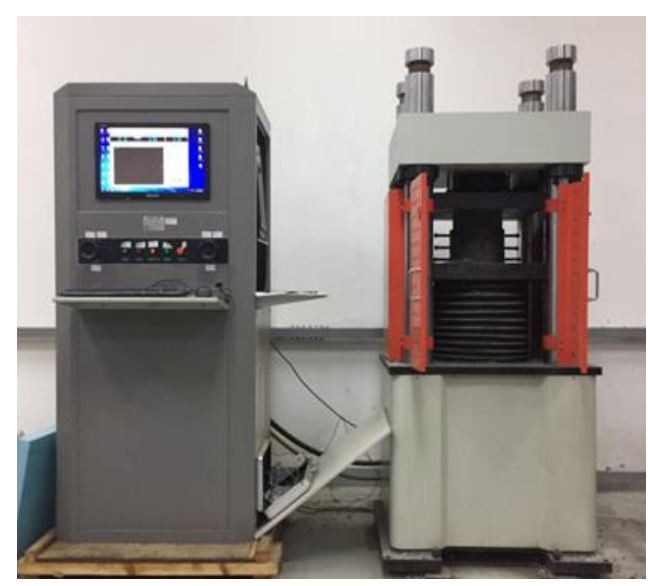

Figure 3. Universal testing machine.

\subsection{Dimensions}


All the concrete paving blocks in this series of experiments were manufactured by a small hydraulic brick making machine. The size of molds in the machine is $200 \mathrm{~mm} * 100 \mathrm{~mm} * 60 \mathrm{~mm}$. In this case, all the blocks' dimensions are $200 \mathrm{~mm}^{*} 100 \mathrm{~mm}^{*} 60 \mathrm{~mm}$, and the error of each side was less than $2 \mathrm{~mm}$. Figure 4 and figure 5 show the front and side faces of one concrete paving block.

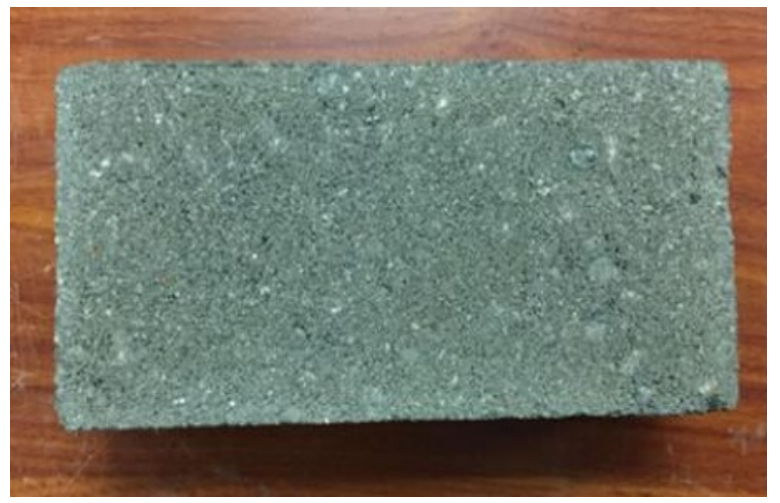

Figure 4. Front face of concrete paving block.

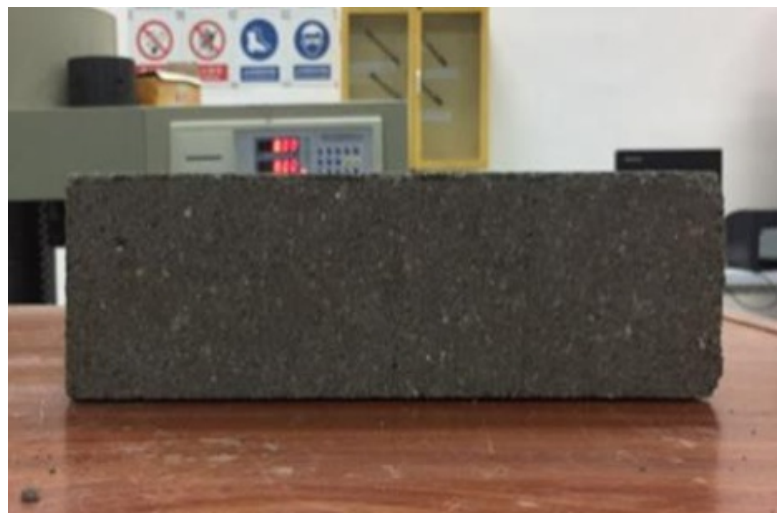

Figure 5. Side face of concrete paving block.

\subsection{Compressive strength}

Figure 6 shows the relationship between the different replacement levels of materials and the compressive strength of specimens.

Specimens mixed with RCCA maintained a stationary compressive strength until the replacement level reached $40 \%$. The compressive strength fluctuated as $41.07 \mathrm{MPa}$, $38.04 \mathrm{MPa}$ and $40.38 \mathrm{MPa}$ when replacement levels were $0 \%, 20 \%$, and $40 \%$ respectively. After the replacement levels were higher than $40 \%$, the compressive strength almost linear decreased from $40.38 \mathrm{MPa}$ at $40 \%$ to 21.04 MPa. According to the BS EN 1338 [10], the compressive strength of concrete paving blocks should equal or higher than $30 \mathrm{MPa}$, which indicated that the specimens with replacement level higher than $60 \%$ were not meet the specification [11].

As another material replacing the coarse aggregates in this series of experiments, the crushed glass had a positive impact on the concrete paving blocks' compressive strength. According to the figure 6 results, the specimens had a higher compressive strength when the replacement levels of crushed glass were $10 \%, 20 \%, 40 \%$ and $60 \%$, and the strength peak the highest value, $43.45 \mathrm{MPa}$, at the replacement level equals $20 \%$.

\subsection{Tensile splitting strength}

Figure 7 demonstrates the relationships between the different research materials' replacement levels and the tensile splitting strength of concrete paving blocks.

Specimens mixed with RCCA had an even higher tensile splitting strength $11.73 \mathrm{MPa}$ at replacement level was $20 \%$. However, the tensile splitting strength almost linear decreased from $11.73 \mathrm{MPa}$ to $8.80 \mathrm{MPa}$ when the replacement level increased from $20 \%$ to $80 \%$ and bottomed at $6.37 \mathrm{MPa}$ with $100 \%$ RCCA in the specimen.

According to the test results, using crushed glass as the coarse aggregates in the concrete paving blocks had a positive effect on the blocks' tensile splitting strength. The overall tendency was that the tensile splitting strength kept increasing with the replacement level changed from $10 \%$ to $40 \%$, and reached the highest value $12.79 \mathrm{MPa}$ at $40 \%$. When the replacement level was $30 \%$, the tensile splitting strength was only $11.38 \mathrm{MPa}$. However, this value was still a little bit higher than the blocks mixed with natural aggregates.

\subsection{Water absorption}

According to figure 8 , it is clear to observe that for the blocks mixed with RCCA, the increase of the replacement levels of the material increases the specimens' water absorption. Furthermore, for blocks mixed with the RCCA, the water absorption value could maintain 3.91\% at the replacement levels $20 \%$, and then peaked $7.60 \%$ while the replacement levels were $100 \%$.

Crushed glass is proved to be a material that can reduce the water absorption when it mixed into blocks. The values of water absorption ranged from $3.50 \%$, $3.24 \% 3.65$ and $3.72 \%$ while the replacement levels were $10 \%, 20 \%, 30 \%$ and $40 \%$.

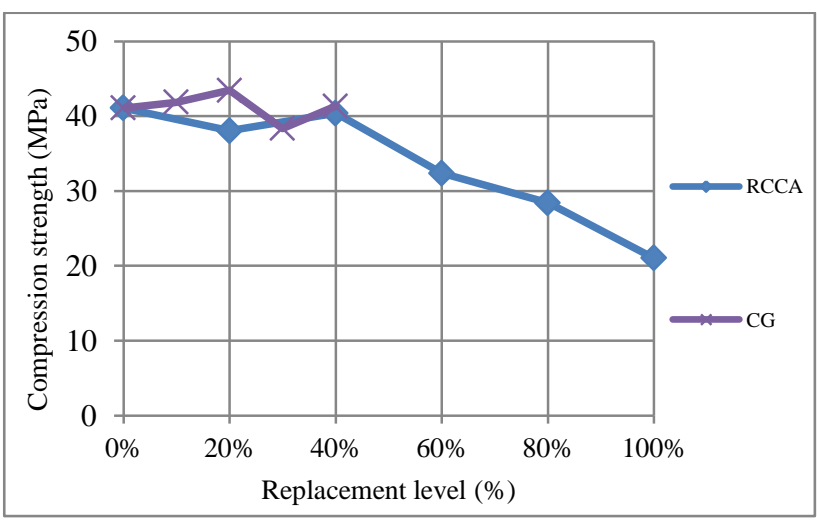

Figure 6. Relationship between the different replacement levels of materials and the compressive strength of specimens 


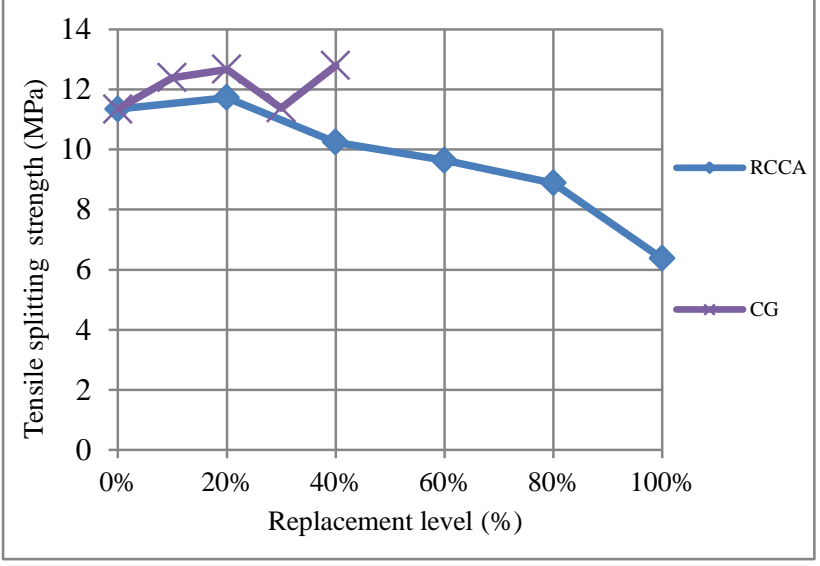

Figure 7. Relationship between the different replacement levels of materials and the tensile splitting strength of specimens.

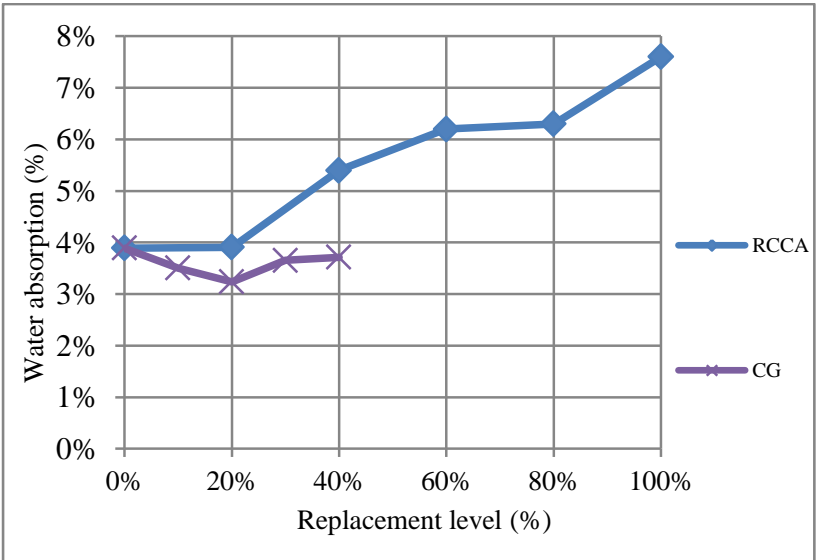

Figure 8. Relationship between the different replacement levels of materials and the water absorption of specimens

\section{Conclusions}

According to the experiment results in the properties of concrete paving blocks mixed with different types of recycled wastes, the conclusions can be drawn as follow:

- Using the RCCA as the coarse aggregate of the concrete paving blocks can lead a significant decrease of both compressive strength and tensile splitting strength of blocks, and also increase the water absorption of the concrete paving blocks. In order to meet the standard requirements, the replacement level of RCCA should be less than $60 \%$.

- Replacing the coarse aggregate with crushed glass could enhance the strength of concrete paving blocks. With the replacement level ranging from $10 \%$ to $40 \%$, all concrete paving blocks mixed with crushed glass had higher strength and lower water absorption than the blocks mixed with natural aggregates. When the replacement level of crushed glass at $20 \%$, the concrete paving blocks had a highest compressive strength and lowest water absorption. The tensile splitting strength of concrete blocks reached the maximum value at replacement level of crushed glass equalling $40 \%$.

\section{Acknowledgement}

The authors gratefully acknowledge Xi'an JiaotongLiverpool University for the finical support. We would also like to thank Suzhou Construction Material Recycling Application Co., Ltd for providing recycled concrete aggregates and machine parameters for the experiments.

\section{Reference}

1. Xing Z, Liu Y and Cai N 2011 Research and application benefit for reycled concrete Low Temp. Archit. Technol. 16

2. BS EN 933-11 2012 Tests for Geometrical Properties of Aggregates Austrian Stand. Inst.

3. Zaidi A M A 2009 Assessment of recycled aggregate concrete Mod. Appl. Sci. 347

4. da Silva F M, Gachet Barbosa L A, Lintz R C C and Jacintho A E P G A 2015

5. Ferreira I K, Gachet-Barbosa L A, Cecche Lintz R C, Russo Seydell M R and Jaquiê Ribeiro L C L 2013 Evaluation of the Behaviour of Mortar with the Addition of Rubber Adv. Mater. Res. 742 456-60

6. Knapton J 1988 A review of concrete block pavements at ports in the UK Proceedings, 3rd. International Conference on Concrete Block Paving, Rome pp 380-92

7. Ding $\mathrm{W}$ and Leng F G 2011 Specification for mix proportion design of ordinary concrete (JGJ55-2011)

8. Jin W, Meyer C and Baxter S 2000 "Glascrete"Concrete with Glass Aggregate ACI Mater. J. 97 208-13

9. Soutsos M N, Tang K and Millard S G 2011 Concrete building blocks made with recycled demolition aggregate Constr. Build. Mater. 25 726-35

10. BSI 1338:2003 2003 Concrete Paving BlocksRequirements and test methods Br. Stand. 76s

11. SAC 2012 Precast concrete paving units $G B 28635$ 2012. 